\title{
Analyzing the Effect of Social Internet of Things on Making the Internet Marketing Smart
}

\author{
Mahdi Hemmati ${ }^{1}$ \\ ${ }^{1}$ Computer Engineering Department, Iran University of Science and Technology, Tehran, Iran \\ Correspondence: Mahdi Hemmati, Computer Engineering Department, Iran University of Science and \\ Technology, Tehran, Iran. E-mail: esfehani.mohamad3@gmail.com
}

Received: May 27, 2016

Accepted: June 18, 2016

Online Published:July 20, 2016

doi:10.5539/mas.v10n9p213

URL: http://dx.doi.org/10.5539/mas.v10n9p213

\begin{abstract}
The development of social internet of things in recent years led to widening the data and information scope. A wide scope of new services caused by this procedure. In this regard, a new pattern called the social internet of things is created by integrating the social network and internet of things (IOT) which shows the network communication of things. IOS can put a step toward the marketing world. In this paper, the effect of IoT on internet marketing and making it smart are taken into consideration by considering marketing in human social network.
\end{abstract}

Keywords: Internet of things, social internet of things, Internet marketing, social network

\section{Introduction}

Internet of things is a phenomenon tends to change our life as the internet made change in 1990. IoT integrates several different universal things that are ceaselessly producing information about the physical world. Most of these information are available through standard websites and some recommend the practical programming links for accessing to sensor and activators. Therefore, the IoT technologies make new services available for the final user in different aspects.

Searching any service that is delivered by IoT devices indicates an important point. The number of things connected to the network is increasing which leads to a big searching environment. Moreover, the number of IoT devices are increasing day by day. Currently, communicative models are based on human-things interactions but soon, the communication will be things-to things interaction in a way that things provide complicated services for human benefits. Ultimately, scalability problem occurs due to search in finding a proper thing for a proper service. In order to avoid the scalability of centralized systems, a new pattern was introduced called social internet of things (SIoT). SloT recommends the integration of social network concepts to guidelines of internet of things. In SIoT, any node is a thing that can independently connect the social relationship to other things and based on the rules of the owner.

The analysts estimate that the connected things will be around 25 milliard by the 2020 . Marketers always try to find data and information and they use any resource for collecting the data. More connection leads to more communication and the data production will be more precisely. Thus, marketers will face new flow of data and they will explore the customer's habits by IoT. Therefore they enhance marketing. In the recent years, some researchers studied the social internet of things but still no comprehensive research has studied the effect of IoT on different parameters such as marketing. In this research we try to study the effect of social internet of things on marketing by considering human social network and their effectiveness on marketing and we conclude that the social internet of things can be an effective step toward various marketing.

The introduction of internet of things and social network are discussed in sections 2 and 3. In the section 1-4, questions related to social internet of things are answered. The section 2-4 indicates the benefits by applying the social network principles in the internet of things. Then, various social relationship between things are stated and we analyze the effect of social internet of things on marketing. Finally we make a whole conclusion.

\section{Internet of Things}

The concept of internet of things initially developed through projects of Massachusett technical institute and analytical journals. However, the internet of things initially introduced by Kevin Ashton in 1999. IoT is a wide 
global network including human and things that can communicate and cooperate with others in order to reach a common goal. The main goal of IoT is sharing information about things that shows human life production, transportation, consumption and other details.

Currently, this term shows the merge of physical world with virtual internet work. It means that the IoT is a network among information resources which can be shared between smart things and market institutions in order to increase the productivity and efficacy of services delivered to customers.

\section{Social Network}

The social network is a group of people or organizations that have the same interests or tastes that are connected to reach the special goals such as family, friendship, business relationship and data sharing.

In the social network, the relationships are shown in forms of node and edge graphs in which nodes show the users and edges show the relationship between these nodes. The features of social network indicator is the complex relationship between the nodes in a network.

\section{The Social Internet of Things}

In the recent years, the idea of using the social network elements in internet of things to make things able to independently connect to the social relationships taken into the consideration. The attitude of a motivator is to explore the social oriented approach and to fortify the information gained by things and distributed things that are connected to physical world.

\subsection{The Questions Discussed in Social Internet of Things}

We can understand the SIoT concept and its share in technology better by answering the following questions:

1) What's the goal of combining the social network principles with the real available calculations?

2) Why the social internet of things is the next step?

3) What are the key perspectives about the future- oriented SIoT?

Regarding the first question, it's stated that in the available calculation environments we can collect and process the information from different users by understanding a view about limited intelligence. Therefore we can find the different relationship models between devices and human (human-human, things-things). The goal of these models is supporting a wide service for social communities. In fact, when different scenarios of the things-things relationships provide the global information for these services, the user's confidence for using these services are regarded as the main value in the available calculation environment.

On the other hand, accessing to cooperation is another goal of the social network. Because the shared textual and social data are invested, the presence of people and communities is no longer inactive. They cooperate with each other by publishing data and content with the aim of reaching needs in their daily life. In the SIoT perspective, users and most devices are the main cooperators for providing services.

For the second question it's stated that the available calculations would be as a guideline in the wide domain of devices and smart programs to avoid many challenges people and organizations face with in their daily life. This can be done by connecting people and things with anyone, anything, anywhere and anyplace. Though the IoT studies consider the relationship with physical world by sensors and activators and through different devices newfangled, the SIoT pattern increases the concerns about why and how these services are used. About the third question it's stated that the certain point of views should be taken into consideration in order to achieve the real integrated relationship between the social world and IoT and in order to achieve the developed benefits by SIoT perspective.

\section{Applying the Internet Network Principles in to IoT}

In fact, applying the internet network principles into IoT can have some advantages:

- The SIoT can be desirably designed to guarantee the ability of network direction. Therefore, exploring things and services can be done efficiently and the scalability can be guaranteed such as human social networks.

- A level of confidence can be established among friendly things for increasing the communication.

- The designed model can be used again for solving the problems related to IoT.

\section{Various Social Relationship between Things}

Luigi Atzori et al, studied different relationship between things that can be seen as follows: 
- Parental Object Relationship (POR): It belongs to the same production class such as Homogeneous things that are produced at the same time by a producer.

Co-location Relationship (C-LOR) occurs between homogenous or heterogeneous things and always in a place (such as sensors, activators and augmented objects that are used in a place such as smart houses or cities). In certain subjects, these relationship occurs among things that their cooperation for a goal seems impossible. However, their existence is useful for filling the network with short links.

- Co-work Object Relationship (C-Wor): It occurs when things cooperate for providing IoT (i.e., when things cooperate to be used in practical programs such as urgent answer or distant treatment).

- Ownership Object Relationship (OOR): It occurs among heterogeneous things belong to a user (heterogeneous things of a user can be cell phones, music players, game, etc.).

- Social Object Relationship (SOR): It occurs among things that are related to each other because their owners are in contact with each other (such as devices and sensors belong to friends, coworkers, classmate, etc.).

\section{The Effect of Social Internet of Things on Marketing}

Marketing and strategies have always been under the influence of technologies. By the emersion of new technologies, the marketing methods also change and by the emersion of SIoT, marketing will enhance. By the growth of IoT, we can find more information from customers.

You can perceive how the customer looks at an experience by IoT (Since the customer enters to a shop, when he/she buy a product to the time he or she uses it). Finally you know what more to do for that product of service and what feature of service can repeat the customer's experience. Therefore, by accessing to the related information (relating to how and why someone buys a product) marketers can organize their marketing efforts toward special customers.

In social network marketing, the purchase chain is long and much more time is needed for decision making. However, customers can show their immediate feedback about a product or service. Marketers can do a quick analysis by these feedbacks.

The IoT-based service can create an environmental intelligence for a wide range of users when they are combined with business services. The IoT devices can order a substitute for themselves and this smart substitute can make marketing smart by IoT.

A SIoT is based on this idea that each thing can find a desirable service by their relationship, asking friends and friends of friends, etc. so that it can efficiently guarantee an exploration method such as those principles that are among human's social network. Based on this pattern, each thing should save and manage the information related to a friend and also apply the search environs. Finally, it should use additional tool such as trustworthiness module for evaluating trustworthiness of each friend. In previous decade, most marketers had not convinced in using social networks (such as Facebook) for their marketing goals. Later, social network marketing changed to a competitive advantage. Currently, IoT is optimized for using with social media and by using these automatic sharing, the marketers can trace customers who were not available before.

In 2014, the Salesforce website reported that there's five ways that IoT can help the marketing intelligence and return the marketing assets. It also reports that soon or later, IoT changed to a concept bigger than smart fridge, environmental warning and wearable technologies. IoT affects our business method specially marketing. Five methods that can improve the asset's return are suggested as follows:

1) Ease of sale's data exchange: one of the most important product of each business is the sale data. By accessing to information (where and how a product is sold), the salespeople can focus their marketing efforts on special customers. Smart devices can collect data and deliver it to salesperson immediately and without the help of technological expert. More importantly, salespeople can save their feedback about a product and he does not need the time for recognizing their product's acceptance. If a product does not meet the customer's need, the salesperson can collect them all from the market.

2) A management system for making relationship with smarter customer: in combination of the IoT with management system of connecting with customers, IoT can collect and organize the data and analyze them efficiently and accurately. Since the choice chain to decision is a long process, it's very worthy for marketers. The IoT devices can make this process simple in a way that can help the marketer understand the customer's expectation about a product. Therefore the marketers can rely on customers in solving problems and come closer to the product sale. 
3) Devices that know their life ending: one of the good point of the smart product is their potential for repairing and finding the error of themselves. The devices of internet of thing can remove a product's failure because they are always checking their performance and when necessary, they call the technical supporter. When a problem cannot be solved, that device can order another device.

4) The predictive social network: IoT is currently used for the optimized social network that can release user's comments of a special devices and they can make a new community. The combination of IoT devices with social networks enables marketers to identify newfangled processes and to make use of them.

5) Advertisement: the goal of all factors is the smarter and more related advertisement. Marketers no longer focus on banners and pop ups. Consequently, the advertisement era would be troublesome from the end of customer and the world would be a place for beneficial advertisement completely relates to the customer's previous behavior, appetite and purchase.

\section{Conclusion}

The IoT affects industry and the size of the produced data and the network is going to increase. Therefore, its popularity among customer related concept is increasing. Moreover, the IoT made changes in the business operations (which could be less desirable for customers) for example from logestic to product advertisement. The new era of marketing is the era of data-driven marketing and the immediate feedback of customers. The marketers can use data this way:

- Analyzing the customer's purchase habits through ways that they use.

- Collecting previous inaccessible data about ways customers got connected to devices and production.

- Accessing to a better vision about the purchase process and to which step the customer is.

- $\quad$ Providing the immediate informing messages of POS and the related advertisement.

- The customer's service in a way that the problems can be solved.

As it was suggested, all these benefits are gained by the marketers using IoT which is suggested in data- oriented marketing.

If we try to combine the social network concepts with the cases suggested above, we will have a social network of the products. The products can advertise each other by the use of customer's feedback (i.e., immediate feedback) or even recognize the unsuccessfulness of the product on the market and help customers in purchasing them. This is only an example of benefits of combining social network with marketing IoT. Surely, if each suggested factor be combined with Iot, the outcome, sale and marketing will be in its highest level.

\section{Reference}

Atzori, L., Iera, A., \& Morabito, G. (2010). The internet of things: A survey. Computer Networks, 54, 2787-2805.

Atzori, L., Iera, A., \& Morabito, G. (2011). SIoT: Giving a Social Structure to the Internet of Things. Communications Letters, IEEE, 15, 1193-1195.

Atzori, L., Iera, A., Morabito, G., \& Nitti, M. (2012). The Social Internet of Things (SIoT) - When social networks meet the Internet of Things: Concept, architecture and network characterization. Computer Networks, 56, 3594-3608.

Bodendorf, F., \& Kaiser, C. (2009). Detecting opinion leaders and trends in online social networks. Paper presented at the Proceedings of the 2nd ACM workshop on Social web search and mining, Hong Kong, China.

Chan, H. C. (2015). Internet of Things Business Models. Journal of Service Science and Management, 8, 552.

Dar, K., Taherkordi, A., Baraki, H., Eliassen, F., \& Geihs, K. (2015). A resource oriented integration architecture for the Internet of Things: A business process perspective. Pervasive and Mobile Computing, 20, 145-159.

Gubbi, J., Buyya, R., Marusic, S., \& Palaniswami, M. (2013). Internet of Things (IoT): A vision, architectural elements, and future directions. Future Generation Computer Systems, 29, 1645-1660.

Hui, G. (2014). How the Internet of Things Changes Business Models. Harvard Business Review, 4.

Keskin, T., \& Kennedy, D. (2015). Strategies in Smart Service Systems Enabled Multi-sided Markets: Business Models for the Internet of Things. System Sciences (HICSS), 48th Hawaii International Conference on, pp. 1443-1452, 2015.

Kosmatos, E. A., Tselikas, N. D., \& Boucouvalas, A. C. (2011). Integrating RFIDs and Smart Objects into a 
UnifiedInternet of Things Architecture. Advances in Internet of Things, 1(1), 8.

Leung, S. (2014). 5 Ways the Internet of Things Will Make Marketing Smarter. Retrieved from https://www.salesforce.com/blog/2014/03/internet-of-things-marketing-impact.html

Nitti, M., Atzori, L., \& Cvijikj, I. P. (2014). Network navigability in the social Internet of Things. Internet of Things (WF-IoT), 2014 IEEE WorldForum on, pp. 405-410, 2014.

Nitti, M., Girau, R., Atzori, L., Iera, A., \& Morabito, G. (2012). A subjective model for trustworthiness evaluation in the social Internet of Things. Personal Indoor and Mobile Radio Communications (PIMRC), IEEE 23rd International Symposium on, pp. 18-23, 2012.

Ortiz, A. M., Hussein, D., Soochang, P., Han, S. N., \& Crespi, N. (2014). The Cluster Between Internet of Things and Social Networks: Review and Research Challenges. Internet of Things Journal, IEEE, 1, 206-215.

Yu, Z., \& Jiangtao, W. (2015). An IoT electric business model based on the protocol of bitcoin. Intelligence in Next Generation Networks (ICIN), 18th International Conference on, pp. 184-191, 2015.

Zhang, D., Yang, L. T., \& Hongyu, H. (2011). Searching in Internet of Things: Vision and Challenges. Parallel and Distributed Processing with Applications (ISPA), IEEE 9th International Symposium on, pp. 201-206, 2011.

\section{Copyrights}

Copyright for this article is retained by the author(s), with first publication rights granted to the journal.

This is an open-access article distributed under the terms and conditions of the Creative Commons Attribution license (http://creativecommons.org/licenses/by/3.0/) 